\title{
Revista Conserva:
}

\section{un recuento a 15 años en el mundo editorial de la conservación- restauración en América Latina}

\author{
Centro Nacional de Conservación y Restauración (CNCR)
}

a revista Conserva es la publicación periódica oficial del Centro Nacional de Conservación y Restauración (CNCR), dependiente de la Dirección de Bibliotecas, Archivos y Museos (Dibam) de Chile. Su objetivo es exponer trabajos y reflexiones en torno a la conservación y la restauración del patrimonio cultural.

Se publica una vez al año con artículos originales inéditos, informes técnicos y ponencias presentadas en congresos, además de información sobre las actividades relevantes del CNCR. Dirigida tanto a especialistas como público en general interesados en el tema, Conserva representa una alternativa para exponer las metodologías y criterios empleados para abordar iniciativas de conservación-restauración y revisar críticamente lo que se realiza en este campo profesional.

\section{Antecedentes}

La revista empezó a publicarse en 1997, cuando el CNCR cumplió 15 años de haberse creado. En ese momento, cuando existía una cantidad de conservadores-restauradores que se estaba formando sistemáticamente en Chile y el CNCR había llevado a cabo una política de capacitación en las instituciones vinculadas con el patrimonio cultural a escala nacional, surgió la posibilidad de contar con un medio que difundiera, tanto entre los entendidos en el tema como hacia un público más amplio, los trabajos de aquéllos. Así, Conserva nació como una necesidad y alternativa para incentivar no sólo la exposición de proyectos sino también la investigación y la reflexión.

Desde un principio se buscó que la revista se constituyera en un medio de divulgación que, más allá de Chile, alcanzara todos los países de habla hispana, ya que hasta ese momento había una notable carencia de publicaciones en español y prácticamente no existían revistas de la especialidad en este idioma: en América Latina sólo se publicaba la revista anual Restauración, del Centro Nacional de Restauración de Colombia. 


\section{Autores, contribuciones}

Lograr que la revista se publicara con regularidad y permanencia fue una meta fundamental, y para ello fue importante estimular a los conservadores-restauradores para que expusieran sus experiencias. En los primeros números sólo los especialistas del CNCR escribían los artículos, pero, poco a poco, en la medida en que la revista se fue conociendo, se invitó a participar a profesionales tanto del país como del extranjero, cuyos aportes han aumentado de manera significativa. Cada número de la revista contiene ocho artículos en promedio, $y$, actualmente, por lo menos uno corresponde a un autor extranjero.

A lo largo de 17 años de publicación ininterrupida son evidentes los logros: hasta el año 2011 Conserva ha publicado 121 artículos escritos por 219 autores (77 han colaborado con más de un artículo). Los profesionales del CNCR han aportado $46 \%$ de los artículos; otros autores nacionales, 39\%, mientras que autores extranjeros han publicado $15 \%$ del total. De las contribuciones del extranjero (67\%), los países que lideran la publicación son Argentina, México y Bolivia. Además, no debemos dejar de mencionar la participación de países como Brasil, España, Colombia, Cuba, Venezuela, Japón y los Estados Unidos.

\section{Contenidos de los artículos}

Si bien en el comienzo los temas de los artículos publicados por Conserva se orientaban fundamentalmente a dar cuenta de los proyectos en los que participaba el CNCR: de investigación, de conservación preventiva, de conservación directa y de restauración de objetos o colecciones arqueológicas, históricas y artísticas, desde el año 2000 se han incorporado temas vinculados con la teorización del patrimonio cultural, el desarrollo de las profesiones dedicadas a su estudio, así como a la formación del conservador-restaura-

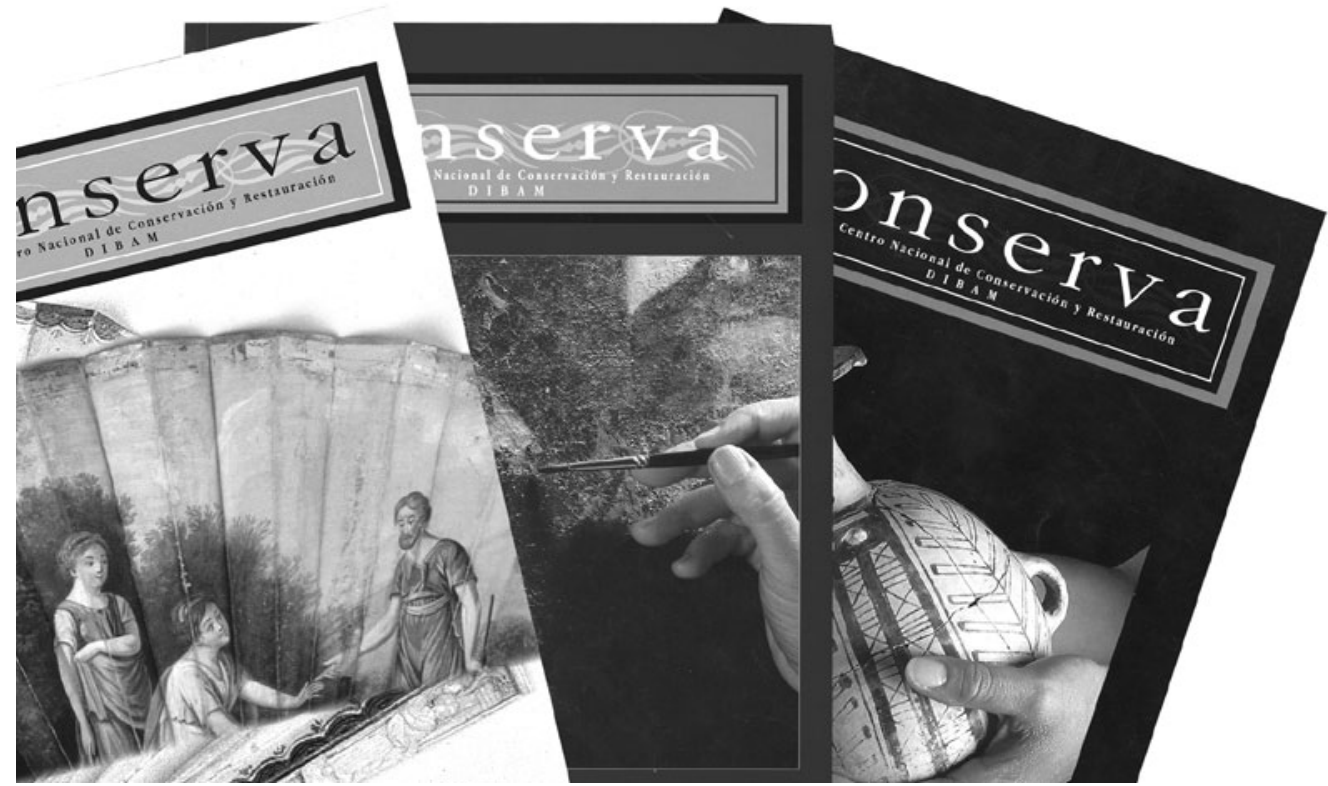

FIGURA 1. Portadas de la revista Conserva (Cortesía: Archivo CNCR, 2012).

dor, y en las últimas ediciones se han posicionado contribuciones que examinan las complejas relaciones entre el patrimonio y la sociedad, el territorio y el paisaje, etc.

Si se analiza la frecuencia en que aparecen palabras claves en las colaboraciones, se deduce que, hasta ahora, la mayor cantidad de éstas han versado sobre intervenciones en pintura (18); en papel y colecciones de archivos y bibliotecas (15), en artefactos y monumentos arqueológi$\cos (12)$, en bienes culturales ubicados en comunidades (11), así como sobre el desarrollo de análisis científicos (9); aspectos de gestión y educación en materia patrimonial también se han hecho presentes, pero con menor frecuencia.

\section{Comité editorial}

El comité editorial de la revista, integrado por profesionales internos y externos al CNCR — quienes varían de acuerdo con el ramo de los artículos recibidos-, asesora a la editora general en la selección de los artículos y revisa críticamente los trabajos. Han participado en este comité 98 especialistas provenientes de instituciones relevantes de Argentina, Bélgica, Brasil, España, los Estados Unidos, Inglaterra, México y Uruguay, ade- más de Chile. La primera editora y gran impulsora de Conserva fue la encargada de la biblioteca del CNCR, Adriana Sáez Braithwaite.

A principios de 2013 se decidió crear un comité editorial permanente, conformado por especialistas del CNCR y académicos externos a la institución, nombrando a Roxana Seguel, jefa del Laboratorio de Arqueología del CNCR Como editora general. Uno de los desafíos que se ha propuesto este comité editorial es avanzar paulatinamente en el cumplimiento de los criterios, políticas y procedimientos para la postulación, aceptación y permanencia de la Revista Conserva en Scielo, biblioteca electrónica que indiza una colección seleccionada de revistas científicas chilenas, en todas las áreas del conocimiento (www.scielo.cl).

\section{Permanencia y difusión}

Un factor importante para la permanencia de la revista fue la política decidida del CNCR de establecer un presupuesto anual destinado a su publicación. Se comenzó con un tiraje de 500 ejemplares y actualmente es de 750 . La revista se envía a las principales instituciones y especialistas del país $(77 \%)$ y del extranjero $(23 \%)$ vinculados con la 
conservación, la restauración y la investigación en el campo de los bienes patrimoniales. La distribución ha sido gratuita o se ha utilizado como medio de canje.

Para su más amplia difusión, cada entrega de Conserva está disponible en pdf en la página web del CNCR [www.cncr.cl] cuyas estadísticas de acceso indican que un porcentaje importante de usuarios lo hacen para leer la revista. Conserva está indexada en Abstracts of International Conservation Literature: [http://aata. getty.edu/Home], y en Bibliographic
Database of the Conservation Information Network (BCIN), base de datos bibliográfica de información con recursos sobre conservación, preservación y restauración de bienes culturales: [www.bcin.ca/English/home _english.html].

En la actualidad se pretende aumentar la difusión de la revista en el ámbito latinoamericano, sumar aportes de experiencias fuera de Chile, de manera que fomente los vínculos y el intercambio de conocimientos, ampliando las redes de comunicación y contacto entre conservadores-res- tauradores e instituciones relacionadas con el patrimonio cultural de todo el continente americano. Por último, un objetivo estratégico es indexar la revista en Scielo, con ello Conserva busca consolidar su lugar como una de las principales publicaciones periódicas en el área de la conservación-restauración en la región latinoamericana. ${ }^{1}$

\footnotetext{
1 Para mayor información sobre Conserva: revista.conserva@cncr.cl
}

\section{Resumen}

En esta semblanza se presenta un breve recuento sobre la historia y actualidad de la revista del Centro Nacional de Conservación y Restauración de Chile (CNCR), Conserva. Un balance sobre los avances logrados desde sus inicios, en 1997, pone en evidencia que un desarrollo a más de 15 años de edición ininterrumpida ha transformado a Conserva en una de las principales publicaciones periódicas del área de la conservación y restauración en América Latina.

\section{Palabras clave}

Conserva, CNCR, conservación-restauración, publicaciones periódicas.

\section{Abstract}

This paper briefly describes the history and current situation of Conserva, a journal edited by the Centro $\mathrm{Na}$ cional de Conservación y Restauración (National Centre for Conservation and Restoration), Chile. An evaluation of its achievements, since its beginning in 1997, shows that more than 15 years of uninterrupted publication has transformed Conserva into one of the leading periodical journals in the field of conservation and restoration in Latin America.

Key words

Conserva, CNCR, conservation-restoration, periodical journals.

Título en inglés: Conserva Journal: 15 years in the publishing world of conservation-restoration in Latin America 